\title{
U⿱宀⿻三丨口
}

\section{Fundamental Electrochemical Properties of Carbon Nanotube Electrodes}

Papakonstantinou, P., Kern, R., Robinson, L., Murphy, H., Irvine, J., McAdams, ET., McLaughlin, JAD., \& McNally, T. (2006). Fundamental Electrochemical Properties of Carbon Nanotube Electrodes. Fullerenes, Nanotubes and Carbon Nanostructures, 13(2), 91-108. https://doi.org/10.1081/FST-200050684

Link to publication record in Ulster University Research Portal

\section{Published in:}

Fullerenes, Nanotubes and Carbon Nanostructures

Publication Status:

Published online: 16/08/2006

DOI:

10.1081/FST-200050684

\section{Document Version}

Publisher's PDF, also known as Version of record

\section{General rights}

Copyright for the publications made accessible via Ulster University's Research Portal is retained by the author(s) and / or other copyright owners and it is a condition of accessing these publications that users recognise and abide by the legal requirements associated with these rights.

\section{Take down policy}

The Research Portal is Ulster University's institutional repository that provides access to Ulster's research outputs. Every effort has been made to ensure that content in the Research Portal does not infringe any person's rights, or applicable UK laws. If you discover content in the Research Portal that you believe breaches copyright or violates any law, please contact pure-support@ulster.ac.uk. 
This article was downloaded by: [University of Ulster]

On: 23 November 2009

Access details: Access Details: [subscription number 909444082]

Publisher Taylor \& Francis

Informa Ltd Registered in England and Wales Registered Number: 1072954 Registered office: Mortimer House, 3741 Mortimer Street, London W1T 3JH, UK

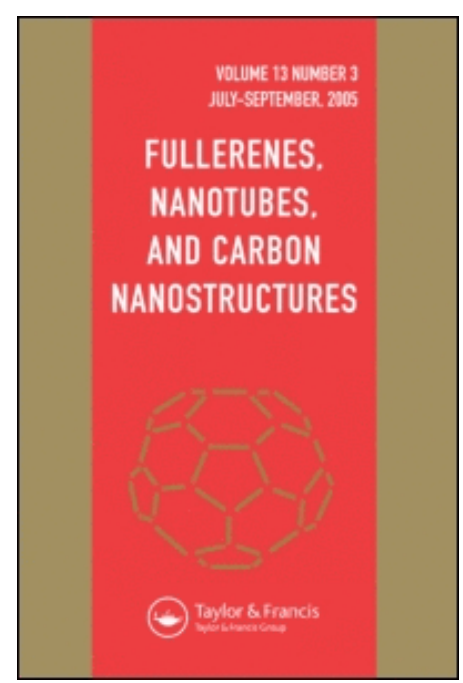

\section{Fullerenes, Nanotubes and Carbon Nanostructures}

Publication details, including instructions for authors and subscription information:

http://www.informaworld.com/smpp/title content=t713597253

\section{Fundamental Electrochemical Properties of Carbon Nanotube Electrodes}

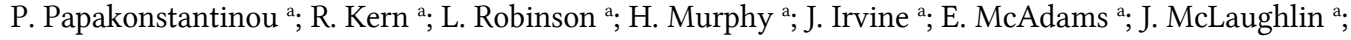
T. McNally ${ }^{b}$

${ }^{a}$ Northern Ireland Bioengineering Centre, NIBEC, University of Ulster, Newtownabbey, Co. Antrim, $\mathrm{UK}^{\mathrm{b}}$ School of Mechanical Engineering, Queen's University Belfast, Belfast, UK

To cite this Article Papakonstantinou, P., Kern, R., Robinson, L., Murphy, H., Irvine, J., McAdams, E., McLaughlin, J. and McNally, T.'Fundamental Electrochemical Properties of Carbon Nanotube Electrodes', Fullerenes, Nanotubes and Carbon Nanostructures, 13: 2, $91-108$

To link to this Article: DOI: 10.1081/FST-200050684

URL: http://dx.doi.org/10.1081/FST-200050684

\section{PLEASE SCROLL DOWN FOR ARTICLE}

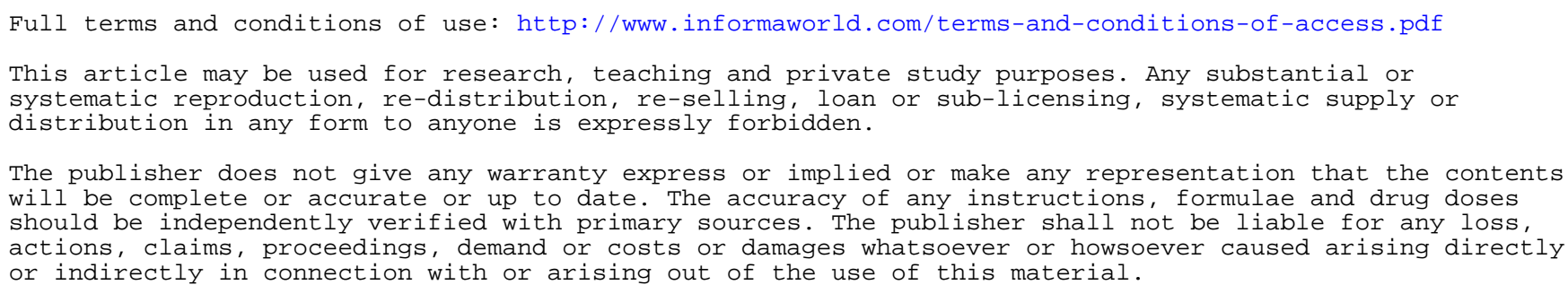


Fullerenes, Nanotubes, and Carbon Nanostructures,

13: 91-108, 2005

Copyright (C) Taylor \& Francis, Inc.

ISSN 1536-383X print/1536-4046 online

DOI: $10.1081 /$ FST-200050684

\title{
Fundamental Electrochemical Properties of Carbon Nanotube Electrodes
}

\author{
P. Papakonstantinou, R. Kern, L. Robinson, H. Murphy, J. Irvine, \\ E. McAdams, and J. McLaughlin \\ Northern Ireland Bioengineering Centre, NIBEC, University of Ulster, \\ Newtownabbey, Co. Antrim, UK
}

\section{T. McNally}

School of Mechanical Engineering, Queen's University Belfast, Belfast, UK

\begin{abstract}
We report on the fundamental electrochemical properties of inherently hydrophobic Multiwalled Carbon Nanotubes MWNT electrodes and acid treated MWNTs. The electrochemical response of the electrodes was investigated by cyclic voltammetry and ac impedance spectroscopy using the redox probe of $\left(\mathrm{Fe}(\mathrm{CN})_{6}^{3-} / \mathrm{Fe}(\mathrm{CN})_{6}^{4-}\right.$, which has well-known kinetic behaviour on carbon surfaces. Comparisons were made between the electrochemical behaviour observed at MWNT electrodes and electrochemically polished glassy carbon, GCE. Confirmation of carbon oxygen functionalities on the surface of acid treated nanotubes was accomplished by X-ray photoelectron spectroscopy. Slow electron transfer kinetics with a peak separation larger than $200 \mathrm{eV}$, and an electron transfer resistance of approximately $370 \Omega$ were observed on pristine MWNTs. However acid treatment was found to significantly improve the electron transfer kinetics of $\mathrm{Fe}(\mathrm{CN})_{6}^{-3 /-4}$ redox couple, approaching almost reversible ET kinetics. Acid treatment modifies the charge carrier density at the surface by introducing surface states and serves to facilitate electron transfer. The better wetting properties of functionalised carbon nanotubes and the higher local density of states as compared to untreated MWNT could be responsible for favouring faster ET kinetics.
\end{abstract}

Keywords: Electrochemical sensors, oxidation, impedance spectroscopy, acid treatment, electron transfer kinetics

Address correspondence to P. Papakonstantinou, Northern Ireland Bioengineering Centre, NIBEC, University of Ulster, Newtownabbey, Co. Antrim BT37 0QBUK, UK. E-mail: p.papakonstantinou@ulster.ac.uk 


\section{INTRODUCTION}

Very few studies have been focused on understanding the factors that govern electron transfer kinetics on carbon nanotubes. These electrode materials are challenging to investigate because they can be single walled, multi-walled, they can contain a large number of defects, functional groups, low level of carbon and/or metal impurities, and their conductivity can vary from metallic to semiconducting depending on diameter and the orientation of the carbon hexagons with respect to the tube axis (chilarity). All these parameters can affect the electrochemical response of CNT electrodes in a complex manner. The multiple defects, carbon phases and orientations could provide discrete sites for heterogeneous electron transfer. Electron transfer kinetic studies are important for the use of carbon nanotubes in several electrochemical applications including electroanalytical sensors, fuel cells and biosensors.

Unlike the more well-studied (1-4) carboneous electrodes (e.g., highly ordered pyrolytic graphite, glassy carbon, and carbon fibers) the elucidation of structure/reactivity relationships for carbon nanotube surfaces is still in its infancy. A prerequisite to determining ET mechanisms at carbon electrodes is the preparation of reproducible and hopefully well defined surfaces. Hence surface preparation is very critical to the performance of electrodes, its stability and reproducibility of results. In addition, the extent to which surface structure affects a redox reaction depends also upon the nature of the analyte. For example, many redox reactions are catalyzed by specific interactions with surface oxides (1).

One of the major thrusts of nanotube research over the past few years has been chemically induced modification (functionalization) to impart solubility and processibility. Besides improving the solubility and processibility, functionalization opens the opportunity for altering the structural and electronic properties (5-7) of CNTS and affords new types of nanotube based materials with useful properties.

Nitric acid is the standard reagent for purification of nanotubes and has traditionally constituted the first step in many different purification schemes. It has been demonstrated that nitric acid removes the transition metal catalyst, that is used in the production of carbon nanotubes, together with amorphous carbon. However it produces a significant destruction in the structure of carbon nanotubes and introduces $-\mathrm{COOH}$ and $-\mathrm{OH}$ groups at the defect sites, present at the nanotube ends and sidewalls.

In the present study we compared the electron transfer characteristics of MWCNTs electrodes before and after treatment in nitric acid in the $\mathrm{Fe}(\mathrm{CN})_{6}^{-3 /-4}$ redox system. By combining independent measurements of oxide functional groups based on Raman and XPS spectroscopies with observations of kinetic behavior, the relationship between surface functionality and ET rate and sensitivity of redox analyte was revealed. 


\section{EXPERIMENTAL SECTION}

MWNTs with $10-30 \mathrm{~nm}$ diameter, were synthesized by CVD process using acetylene as carbon source and $\mathrm{Fe}-\mathrm{Ni}$ as catalyst. The growth temperature was approximately $750^{\circ} \mathrm{C}$. The as grown MWNTs were rinsed with $\mathrm{HCl}$ and distilled water. The $\mathrm{HCl}$ treated product was composed of $\sim 85 \%, 10 \%$ amorphous carbon and $5 \% \mathrm{NiO}, \mathrm{FeO}$, and $\mathrm{Al}_{2} \mathrm{O}_{3}$. These nanotubes are denoted as pristine nanotubes. MWNTs were further purified by refluxing the pristine nanotubes at concentrated $\mathrm{HNO}_{3}$ for 4 hours. The solid product was collected on a PTFE membrane (Millipore porous filter, $0.2 \mu \mathrm{m}$ ) after diluting with deionized water until the filtrate $\mathrm{pH}$ became nearly neutral. These purified nanotubes are deemed as functionalised.

MWNT suspension was prepared by dispersing 10 milligrams in $10 \mathrm{~mL}$ of organic solvent $N, N$-dimethylformamide (DMF) with the aid of ultrasonic agitation. $20 \mu \mathrm{l}$ of a $1 \mathrm{mgmL}^{-1}$ suspension was dropped onto a freshly cleaned GCE surface and the solvent was then evaporated under an infrared lamp. The GCE surface area was $0.0314 \mathrm{~cm}^{2}$. Pristine nanotubes were non soluble in DMF (were sunk at the bottom after several minutes), while the functionalised ones provided a black solution for several days. To improve homogeneity of the suspensions, these were sonicated for 10 minutes prior to each deposition. Polished GC electrodes were prepared by initial sanding with fine emery paper, then polishing with $0.3 \mu \mathrm{m}$ of alumina slurry, followed by sonication in alcohol for 10 minutes. Subsequently, electrochemical polishing was carried out by poising the electrode at $1.8 \mathrm{~V}$ for 8 seconds in $0.1 \mathrm{M} \mathrm{NaOH}$.

Cyclic voltammetry and electrochemical impedance spectroscopic (EIS) mesurements were carried out at an Autolab electrochemical workstation. The modified GCE electrode was used as a working electrode. The reference electrode was a saturated calomel electrode and a platinum electrode was used as counter electrode. All experiments were conducted by conditioning the electrode through cycling the potential in aqueous electrolytes between -0.2 and $0.7 \mathrm{~V}$ for 7 times at $50 \mathrm{mV} / \mathrm{s}$ followed by electrochemical impedance and cyclic voltammetry measurements. The initial conditioning was found to be sufficient to activate the electrode and create better electrolyte/electrode interface. The redox system used was as follows: $5 \mathrm{mM} \mathrm{Fe}(\mathrm{CN})_{6}^{4-}$ in $1 \mathrm{M} \mathrm{KCl}$ solution made from $\mathrm{K}_{4} \mathrm{Fe}(\mathrm{CN})_{6}$. XPS were obtained using a high resolution ESCA spectrometer.

\section{RESULTS AND DISCUSSION}

\section{Electrochemical Responsiveness in $\mathrm{Fe}(\mathrm{CN})_{6}^{-3 /-4}$ Redox System}

In the present study the GC electrode is modified with nanotubes by drop coating a random tangle of nanotubes onto the electrode surface. This 
method resulted in an unknown spatial distribution of carbon nanotubes on the electrode surface, making a quantitative comparative study between pristine and functionalized nanotubes impossible. In order to get an insight onto the role of nanotube quantity on the electrochemical response, we investigated the effect of successive depositions of the suspension, at the GC electrode surface.

Figure 1 shows cyclic voltammetric I-E curves for $5 \mathrm{mM}$ potassium ferrocyanide GC electrode as a function of the number of successive depositions, of the suspension containing pristine carbon nanotubes. It should be emphasized that the ideal $\Delta \mathrm{E}_{\mathrm{p}}$ value of $59 \mathrm{mV}$ for the GC electrode was highly reproducible only after the electrochemical oxidative procedure. Significant variations in $\Delta \mathrm{E}_{\mathrm{p}}$ values were recorded after the alumina slurry polishing procedure, illustrating the surface to surface variability of polished GC electrode. It is generally accepted that the surface of polished GC is covered with a layer of contaminants, which is composed of carbon microparticles, alumina, and other impurities. This layer is formed during polishing and has been shown to remain even after ultrasonic cleaning. This may be sufficient to induce variation in measured $\Delta \mathrm{E}_{\mathrm{p}}$ values for inner sphere redox systems, like $\mathrm{Fe}(\mathrm{CN})_{6}^{-3 /-4}$, which is known to be surface sensitive.

A number of important points is worth mentioning regarding the cyclic voltammograms of Figure 1. The first one is that by modifying the GC electrode with pristine MWNTs a high surface area is generated which displays a greatly enhanced Faradaic response. The large Faradaic current is of analytical interest and is associated with the redox activity of the

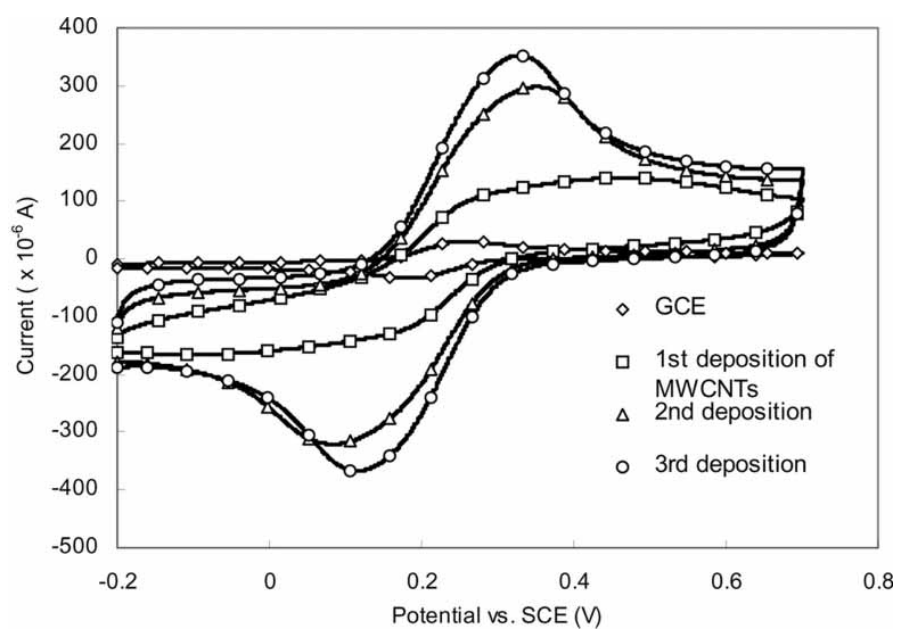

Figure 1. Comparative cyclic voltammetric responses $\left(100 \mathrm{mV} \mathrm{s}^{-1}\right)$ of a glassy carbon electrode to $5 \mathrm{mM} \mathrm{K}_{4} \mathrm{Fe}(\mathrm{CN})_{6}$ before and after successive depositions of pristine MWNTs. 
solution analyte. The increase in the output current is significant upon the first and second deposition. This increase in the current, is related to the enhanced electroactive surface area between initial depositions. However, additional depositions do not cause any prominent change in the peak current. This indicates that two depositions are enough to cover completely the GC electrode area. Any additional amount of pristine MWNTs does alter the electroactive surface area to a significant degree and a maximum current response is obtained according to the Randles-Sevcik equation.

$$
I_{p}=2.69 \times 10^{5} A D^{1 / 2} n^{3 / 2} v^{1 / 2} C
$$

where $I_{p}$ is the peak current, $n$ is the number of electrons participating in the redox reaction, $\mathrm{A}$ is the area of the electrode $\left(\mathrm{cm}^{2}\right)$, D is the diffusion coefficient of the molecule in solution $\left(\mathrm{cm}^{2} \mathrm{~s}^{-1}\right), \mathrm{C}$ is the concentration of the probe molecule in the bulk solution $\left(\mathrm{mol} \mathrm{cm}^{-3}\right)$, and $\mathrm{v}$ is the scan rate of the potential perturbation $\left(\mathrm{Vs}^{-1}\right)$.The $\mathrm{Fe}(\mathrm{CN})_{6}^{-3 /-4}$, redox system exhibits a heterogeneous one electron transfer $(\mathrm{n}=1)$. C is equal to $5 \mathrm{mM}$ and the diffusion coefficient $\mathrm{D}$ is $(6.70 \pm 0.02) \times 10^{-6} \mathrm{~cm}^{2} \mathrm{~s}^{-1}$. Therefore, upon successive depositions the only parameter that changes is A.

The second point is that the peak separation $\Delta \mathrm{E}_{\mathrm{p}}$ for the modified $\mathrm{GC}$ electrodes is larger than $200 \mathrm{~V}$ indicating slow electrode reaction kinetics. The third point is that the larger background currents at the modified GC electrodes would result in reduced signal to noise ratio, which is a drawback for electroanalysis. A linear relationship between peak currents $\left(i_{p}\right)$ values and $\mathrm{v}^{1 / 2}$ were observed at scan rates between 50 and $500 \mathrm{mV} / \mathrm{s}$ (Fig. 2) indicative of reactions limited by semi-infinite linear diffusion of reactants to the electrode surface. However, a large capacitive component of the background current would be favorable for use in supercapacitors. It has been suggested (8) that the signal to background ratio can be optimized by controlling the CNT packing density so that the intertube distance is of the same order of magnitude as the diffusion layer thickness. The higher background current is due to fact that the MWNTs, form a highly permeable porous film and the electrolyte can penetrate through the film and gain access to the interior surface.

Figure 3a presents cyclic voltammetric I-E curves for $\mathrm{Fe}(\mathrm{CN})_{6}^{-3 /-4}$ redox system as a function of successive depositions of functionalized nanotubes on the GC electrode. A reversible response is seen with a $\Delta \mathrm{E}_{\mathrm{p}}$ of $62 \mathrm{mV}$ and an $\mathrm{i}_{\mathrm{p}}^{\mathrm{ox}} / \mathrm{i}_{\mathrm{p}}^{\text {red }}$ of 0.99 for all successive depositions indicating fast electron transfer rates. The $\Delta \mathrm{E}_{\mathrm{p}}$ with the pristine nanotube electrode is about $200 \mathrm{mV}$, much larger than the $62 \mathrm{mV}$ separation, observed with the functionalised MWNT electrode. There are a number of reasons that could play a role on the nearly ideal electron transfer kinetics of the functionalized nanotubes. First, the acid treatment creates more oxide defects on the side walls and make the MWNT more hydrophilic, so that the aqueous solution 

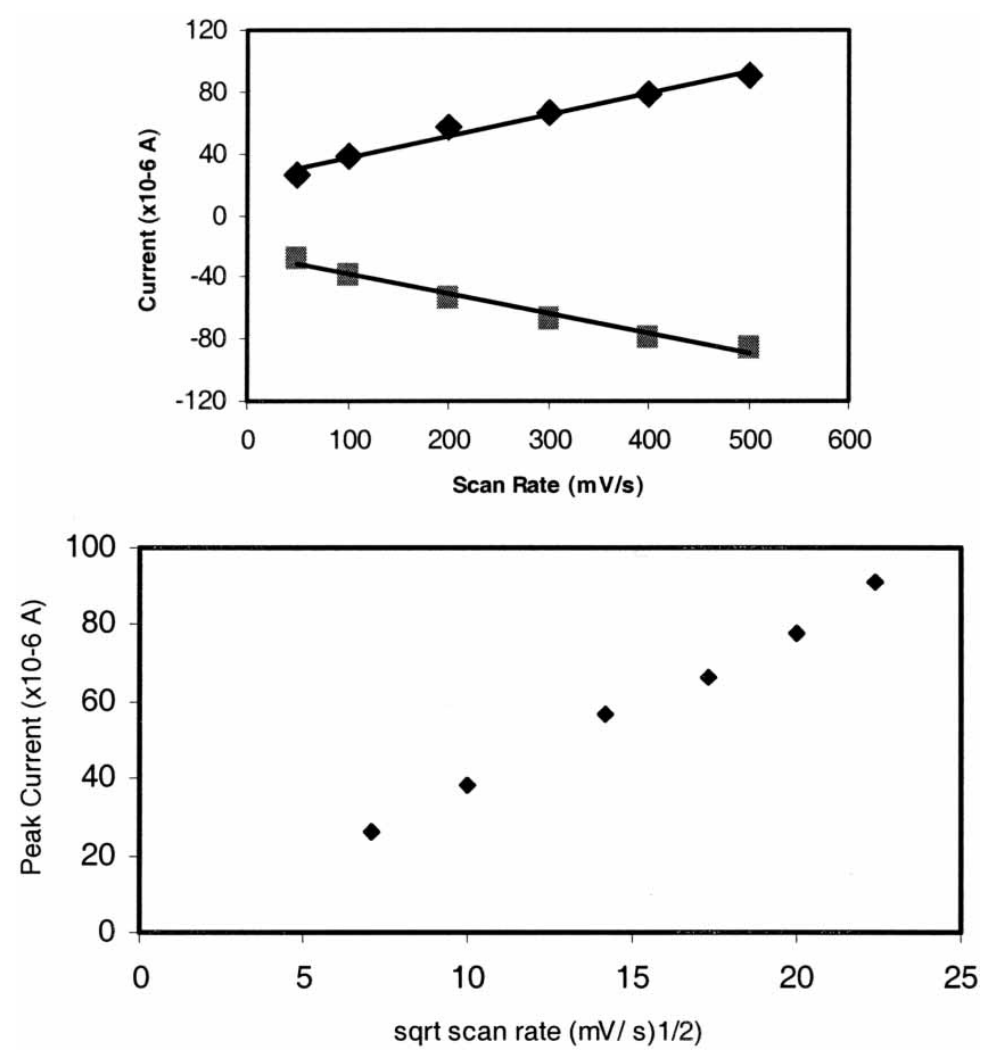

Figure 2. (a)Anodic currents and cathodic peak currents of cyclic voltammetry obtained with a pristine MWNT modified GC electrode vs. scan rate. (b) Fitted anodic peak current of the $\mathrm{Fe}(\mathrm{CN})_{6}^{-3 /-4}$ pair vs. the square root of scan rate.

can contact the surface better. As a result the electron transfer rate can be improved. Second, our XPS measurements revealed that reflux in nitric acid results in partial oxidation of the nanotubes. About $8 \%$ of the surface carbons were bound to oxygen. The functional groups introduced at the nanotube ends and at side wall defects include: $-\mathrm{OH},>\mathrm{C}=\mathrm{O}$, and $\mathrm{COOH}$. It has been shown (9-10) that oxygen exposure can dramatically influence the nanotubes' electrical resistance and local density of states and a semiconducting nanotube can be converted to a metallic one through such exposure. As compared to pristine nanotubes, this increased conductance and higher local density of states of functionalized nanotubes could be responsible for favoring faster ET kinetics. Third, the electrode reaction kinetics for the $\mathrm{Fe}(\mathrm{CN})_{6}^{-3 /-4}$ couple are strongly influenced by the amount of exposed edge planes on $\mathrm{sp}^{2}$ bonded carbon. It has been shown that acid treatment exposes the nanotube ends and therefore it expected that functionalized 

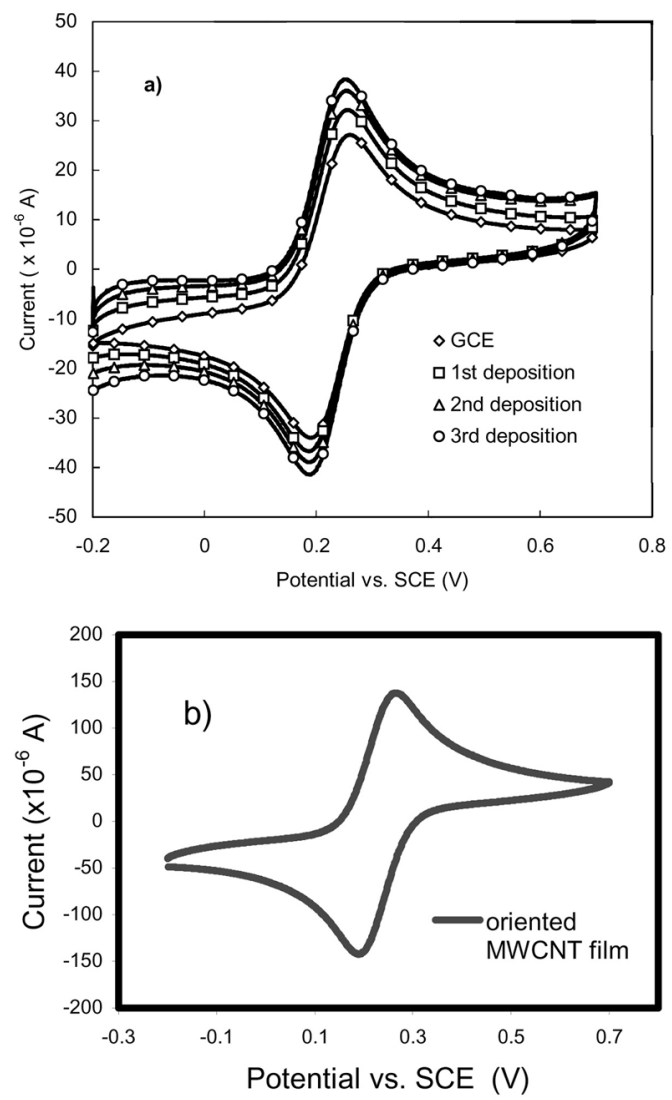

Figure 3. (a) Comparative cyclic voltammetric responses $\left(100 \mathrm{mV} \mathrm{s}^{-1}\right)$ of a glassy carbon electrode to $5 \mathrm{mM} \mathrm{K}_{4} \mathrm{Fe}(\mathrm{CN})_{6}$ before and after modification with successive depositions of functionalized MWNTs. (b) Cyclic voltammetric response from an oriented MWNT film.

nanotubes could contain a larger fraction of exposed edge planes compared to the pristine ones, providing faster ET kinetics. The above results illustrate that the electrode kinetics are highly sensitive to surface termination for the $\mathrm{Fe}(\mathrm{CN})^{-3 /-4}$ redox couple. This is in agreement with studies on both glassy carbon and boron doped diamond.

It should be mentioned that we have also investigated the electrochemical response of as grown vertically aligned MWNTs on a silicon substrate. The MWNTs were synthesized by microwave CVD using Fe as a catalyst layer, at a growth temperature of $1000^{\circ} \mathrm{C}$. We observed ideal Nerstian behavior (presented in Figure 3b) with a $\Delta \mathrm{E}_{\mathrm{p}}$ peak separation of $59 \mathrm{mV}$ for the $\mathrm{Fe}(\mathrm{CN})_{6}^{-3 /-4}$ redox couple even though the sample was not subjected to any pretreatment. The superior performance of these vertically aligned 
MWNTs relative to their entangled counterparts is linked to the combination of electrolyte accessibility, the reduced amorphous carbon contaminants, and increased number of exposed ends (similar to edge plane graphite).

Ideal behavior on as grown MWNTs, synthesized by electric arc discharge, has also been observed by Ajayan and co-workers (11). They investigated the use of as grown MWNT entangled micro bundles as electrodes and shown rapid electrode transfer for oxidation-reduction of the ferroferricyanide couple. However $\mathrm{Li}$ et al. (12) reported $\Delta \mathrm{E}_{\mathrm{p}}$ values of $170 \mathrm{mV}$ and $100 \mathrm{mV}$ for vertically aligned MWNTs electrode and SWNT paper respectively, which were further improved with acid treatment. In their case, the aligned MWNTs were grown by thermal CVD at $750^{\circ} \mathrm{C}$ on Si. It is well known that there is a significant amount of amorphous carbon, graphitic particles and catalyst particles mixed with the MWNTs during thermal CVD, which was confirmed from their TGA results. These impurities along with the detailed structure (diameter, length packing density) of the MWNTs should be responsible for the slow electron transfer kinetics.

The current response of GC electrode changes only slightly with successive depositions of functionalised nanotubes, in contrast to the dramatic change observed for pristine nanotubes. This is related to the large background current of pristine nanotubes.

\section{pH Effects on Voltammetric Response}

In order to understand the kinetics involved we have examined the voltammetric behavior of pristine and functionalised nanotubes at different $\mathrm{pH}$ values. If electrostatic interactions are operative one would expect that the charge of the surface groups on the CNTs to affect the voltammetric behavior in the redox analyte. At acidic $\mathrm{pH}$, the surface of oxygen functionalized CNTs should be neutral. As the $\mathrm{pH}$ is increased above 7 these surface oxide functionalities are expected to be deprotonated, resulting in a negatively charged electrode surface. This charge would repel the highly charged $\mathrm{Fe}(\mathrm{CN})_{6}^{-3 /-4}$ species, increasing the electron tunneling distance and reducing the rate of electron transfer. Therefore at $\mathrm{pH} 10$ the $\Delta \mathrm{E}_{\mathrm{p}}$ for $\mathrm{Fe}(\mathrm{CN})_{6}^{-3 /-4}$ should be larger than at $\mathrm{pH} 1.3$, as has been previously reported by Deakin and co-workers for $\mathrm{sp}^{2}$ carbon electrodes (13). Such an effect was not observed in our measurements presented in Figure 4. Instead an increase in $\Delta \mathrm{E}_{\mathrm{p}}$ was observed at $\mathrm{pH}$ 1.3. The voltammetric wave at both pristine and functionalised nanotubes is shifted to higher potential at acidic $\mathrm{pH}$ 1.3.

The insensitivity of the response to the presence of the surface oxygen carbon functionalities further suggests that the improvement of the $\mathrm{Fe}(\mathrm{CN})_{6}^{-3 /-4}$ kinetics cannot be due to electrostatic effects. If electrostatic effects were dominating then an inhibition of the $\mathrm{Fe}(\mathrm{CN})_{6}^{-3 /-4}$ response 

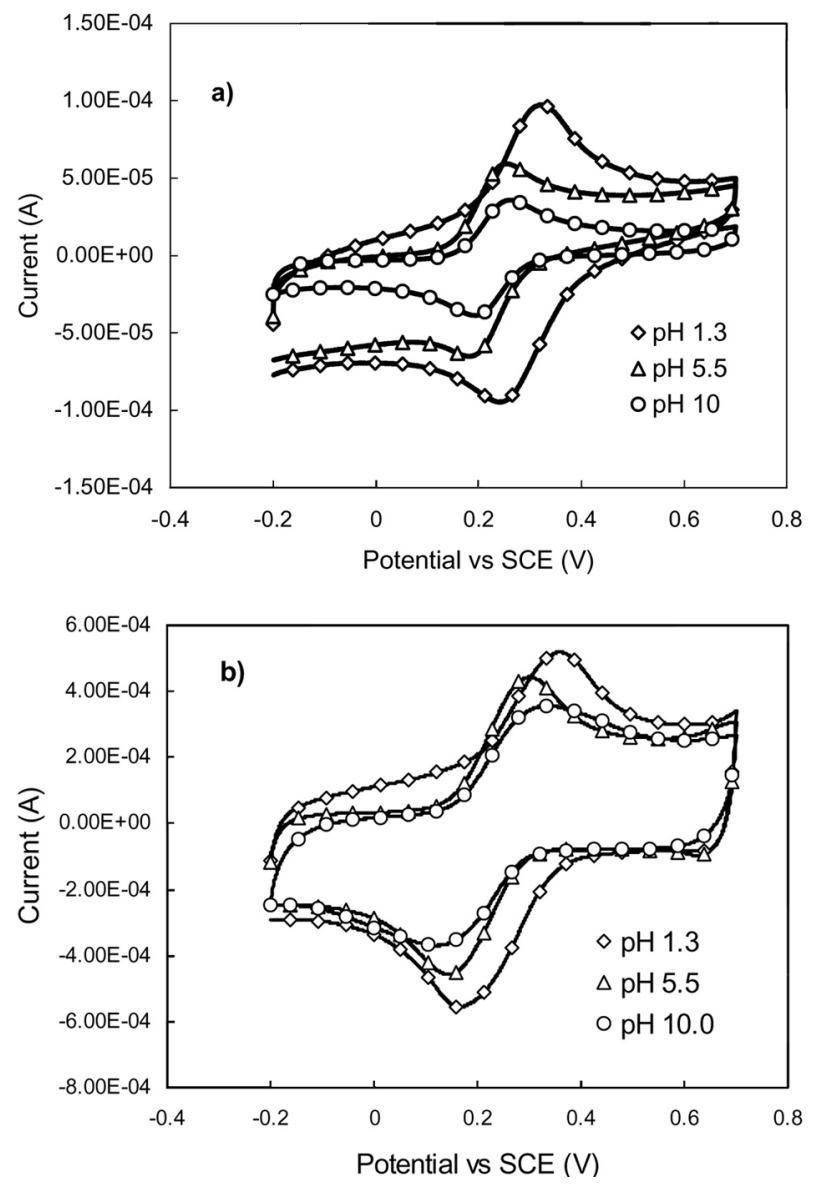

Figure 4. (a) Comparative cyclic voltammetric responses $\left(100 \mathrm{mV} \mathrm{s}^{-1}\right)$ of a modified glassy carbon electrode with a functionalized and (b) pristine MWNTs for $5 \mathrm{mM}$ $\mathrm{K}_{4} \mathrm{Fe}(\mathrm{CN})_{6}$, as a function of the solution $\mathrm{pH}$.

would be expected at high $\mathrm{pH}$ where the surface oxides are deprotonated. Moreover the response for $\mathrm{Fe}(\mathrm{CN})_{6}^{-3 /-4}$ at pristine nanotube electrode should be unaffected by solution $\mathrm{pH}$ because of the absence of ionizable surface oxides.

\section{Impedance Spectroscopy}

Figure 5 displays EIS spectra in the form of Nyquist plot, for a GC electrode before and after modification with successive depositions of pristine MWCNTs. Figure 6 shows the EIS spectra presented in Bode plots where 

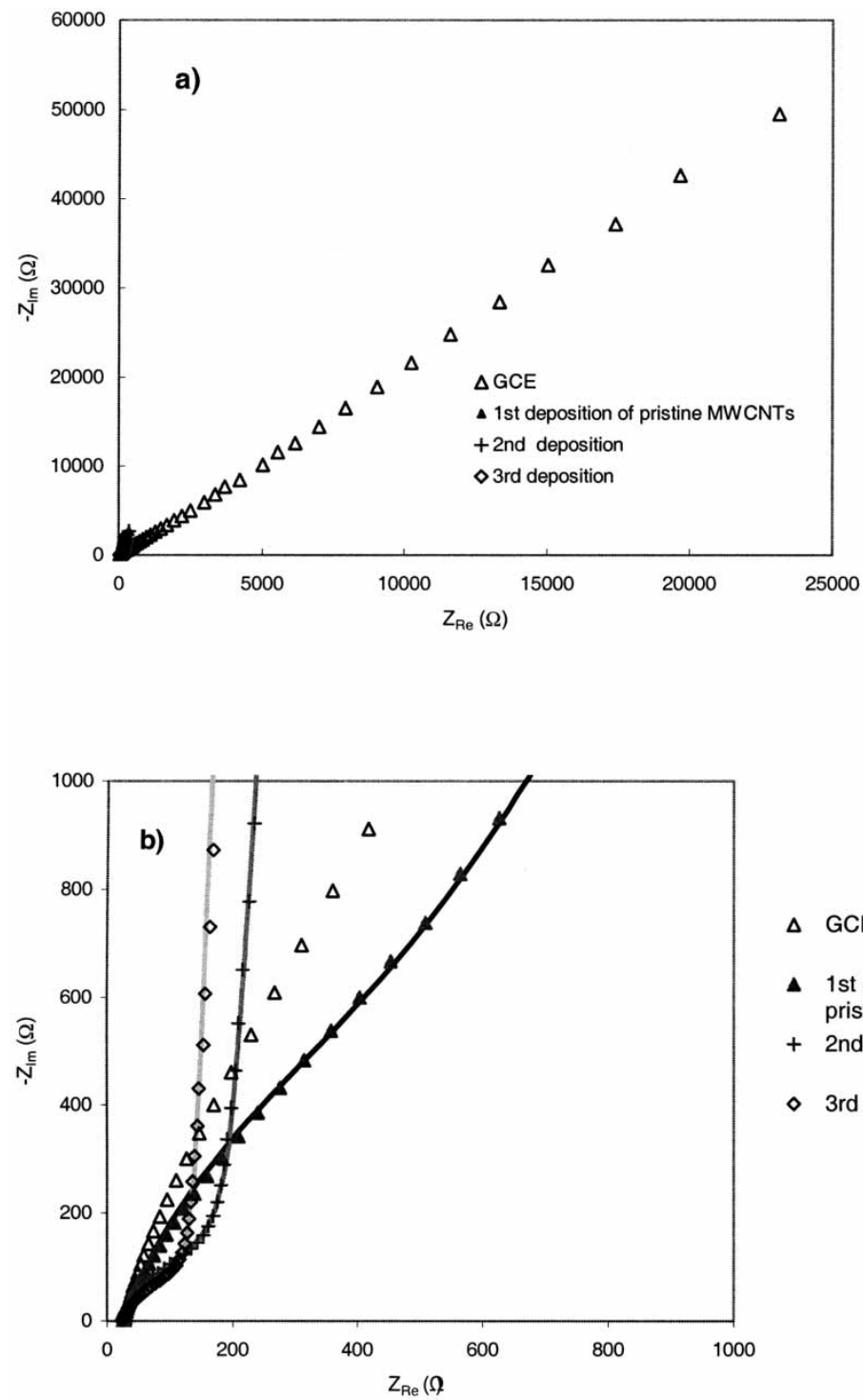

$\Delta$ GCE

1st deposition of pristine MWCNTs

+ 2nd deposition

- 3rd deposition

Figure 5. (a) Impedance spectra in the form of Nyquist plot for a glassy carbon electrode before and after modification with successive depositions of pristine MWNTs measured in the full frequency range of $0.1 \mathrm{~Hz}$ to $90 \mathrm{kHz}$. (b) is a magnified version of the low frequency range.The simulated curves, full lines, are calculated on the basis of an equivalent circuit (see text). 

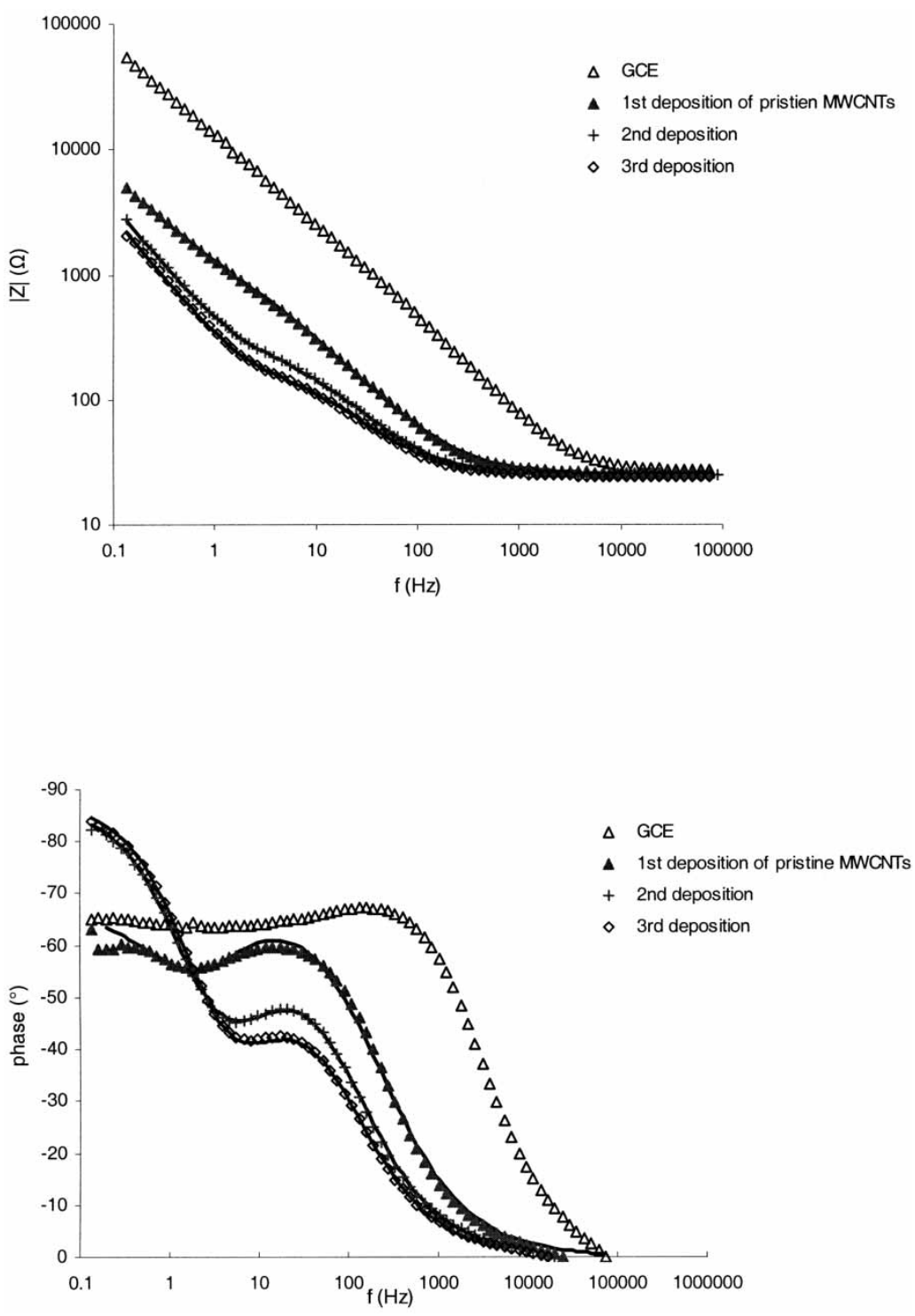

Figure 6. Impedance spectra in the form of bode plots for a glassy carbon electrode before and after modification with successive depositions of pristine MWNTs measured in the full frequency range of $0.1 \mathrm{~Hz}$ to $90 \mathrm{kHz}$. The simulated curves, full lines, are calculated on the basis of an equivalent circuit (see text). 
the impedance magnitude, $|\mathrm{Z}|$ and of the phase angle are plotted vs frequency in logarithmic scale. It should be mentioned that the experiments were repeated several times and the spectra shown are thought to be representative of typical results. There are several important features on the curves that are worth noting. First it is clear that the impedance values measured from the graphite electrode are higher that those of the modified GCE electrodes illustrating the conductive character of the CNT films. Second, the Nyquist plots of GC electrodes modified with two and three depositions consist of a semicircle region at high frequencies followed by an almost vertical line at low frequencies. Third in the high and intermediate frequencies the impedance magnitude decreases systematically with successive depositions.

Interpretation of the EIS measurements is usually done by fitting the impedance data to an equivalent electronic circuit which is representative of the physical processes taking place in the system under investigation. The electrochemical response to impedance tests for the CNT depositions under investigation were best simulated with the equivalent circuit of Figure $7 \mathrm{a}$. The equivalent circuit consists of the following elements: the solution resistance of the electrolyte $\mathrm{R}_{s}$; the double layer capacitance, $\mathrm{C}_{d l}$; the faradaic resistance $\mathrm{R}_{F}$; the pseudocapacitance $\mathrm{C}_{p}$, the capacitance of the surface CNT film formed on the $\mathrm{GC}$ electrode, $\mathrm{C}_{c}$; and the resistance $\mathrm{R}_{c}$ which is the sum of

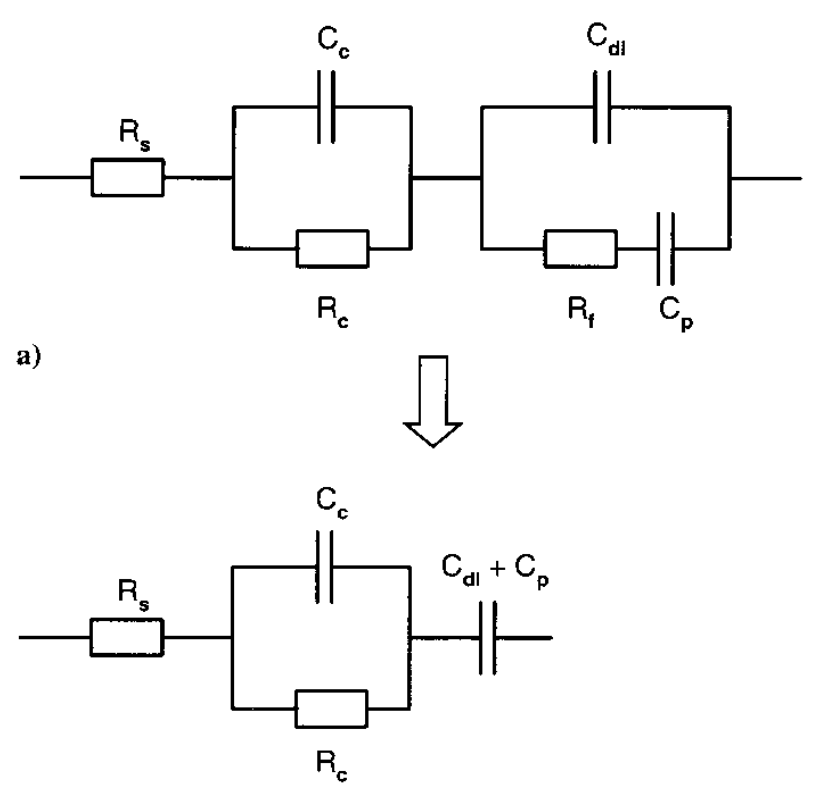

b)

Figure 7. Equivalent circuit used for modeling the EIS spectra. 
the resistance of the CNT film and the contact resistance between the film and the GC electrode. Due to its very large value $\mathrm{R}_{F}$, can be omitted and the circuit can been simplified to that shown in Figure $7 \mathrm{~b}$. The elements of the equivalent circuit representing the coating $\left(\mathrm{C}_{c}\right.$ and $\left.\mathrm{R}_{c}\right)$ can be determined from the high frequency region of the Bode plots, while the elements representing the capacitive behaviour at the electrolyte/electrode interface $\left(\mathrm{C}_{d l}+\mathrm{C}_{p}\right)$ can be determined from the low frequency region.

Table 1 summarises the circuit parameters obtained from the fitting process. In fact, instead of capacitances $\mathrm{C}_{c}$ and $\mathrm{C}_{d l}+\mathrm{C}_{p}$ constant phase elements CPE, which represent the deviation from the true capacitive behavior were used in the fitting process. The impedance of a CPE is represented by:

$$
Z_{C P E}=\frac{1}{C(j \omega)^{a}}
$$

with $-1<\alpha \leq 1$ where $\mathrm{C}$ is a constant, $\omega$ is the angular frequency and $\alpha$ is the CPE power. The better fitting obtained with the use of CPE is related to the surface inhomogeneities of the modified electrode. It can be seen clearly that the coating capacitance $\mathrm{C}_{c}$ value increased, while the $\mathrm{R}_{c}$ values decreased with increasing the number of depositions. The evolution of $\mathrm{C}_{c}$ and $\mathrm{R}_{c}$ values with increasing deposition is in agreement with Equations (3) and (4), which represent the coating capacitance and resistance.

$$
\begin{aligned}
C_{C} & =\varepsilon_{o} \varepsilon_{r} \frac{A}{d} \\
R_{C} & =\rho \frac{d}{A}
\end{aligned}
$$

where $\varepsilon_{r}$ is the dielectric constant of the coating, $\varepsilon_{o}$ is the electrical permitivity of vacuum $\left(8.885 \times 10^{-12} \mathrm{Fcm}^{-1}\right), \mathrm{A}\left(\mathrm{m}^{2}\right)$ is the surface area of the covered working electrode and $\mathrm{d}(\mathrm{m})$ is the thickness of the coating. From Equations (3) and (4) it is obvious that an increase in A will produce a rise in $\mathrm{R}_{c}$ and a fall in $\mathrm{C}_{c}$ in agreement with the data in Table 1.

Figure 8 displays EIS spectra in the form of Nyquist plot for a GC electrode before and after modification with successive depositions of

Table 1. Fitting parameters of the EIS spectra of Figure 1 representing depositions of pristine MWCNTs

\begin{tabular}{llllccl}
\hline & $\mathrm{R}_{\mathrm{s}}(\Omega)$ & $\mathrm{R}_{\mathrm{c}}(\Omega)$ & $\mathrm{C}_{\mathrm{c}}(F)$ & $\alpha_{\mathrm{c}}$ & $\mathrm{C}_{\mathrm{dl}+\mathrm{p}}(\mathrm{F})$ & $\mathrm{a}_{\mathrm{dl}+\mathrm{p}}$ \\
\hline 1st deposition & 25.2 & 346.4 & $2.03 \times 10^{-4}$ & 0.87 & $2.37 \times 10^{-4}$ & 0.76 \\
2nd deposition & 24.7 & 174.5 & $2.49 \times 10^{-4}$ & 0.81 & $4.36 \times 10^{-4}$ & 0.97 \\
3rd deposition & 24.6 & 113 & $2.98 \times 10^{-4}$ & 0.81 & $5.47 \times 10^{-4}$ & 0.98 \\
\hline
\end{tabular}




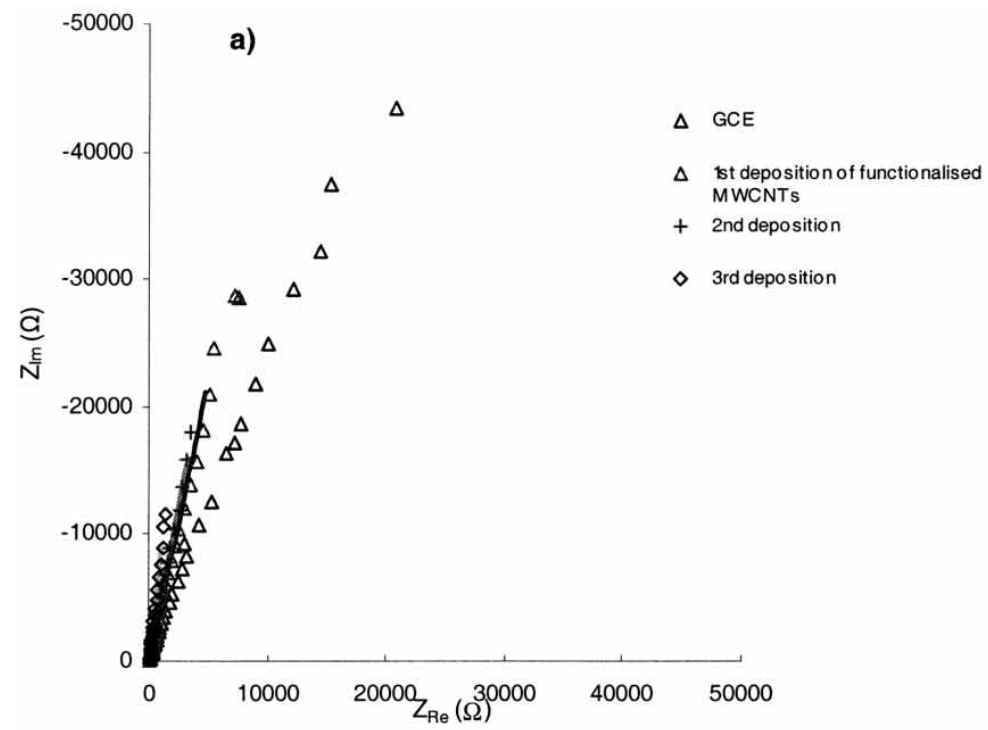

b)

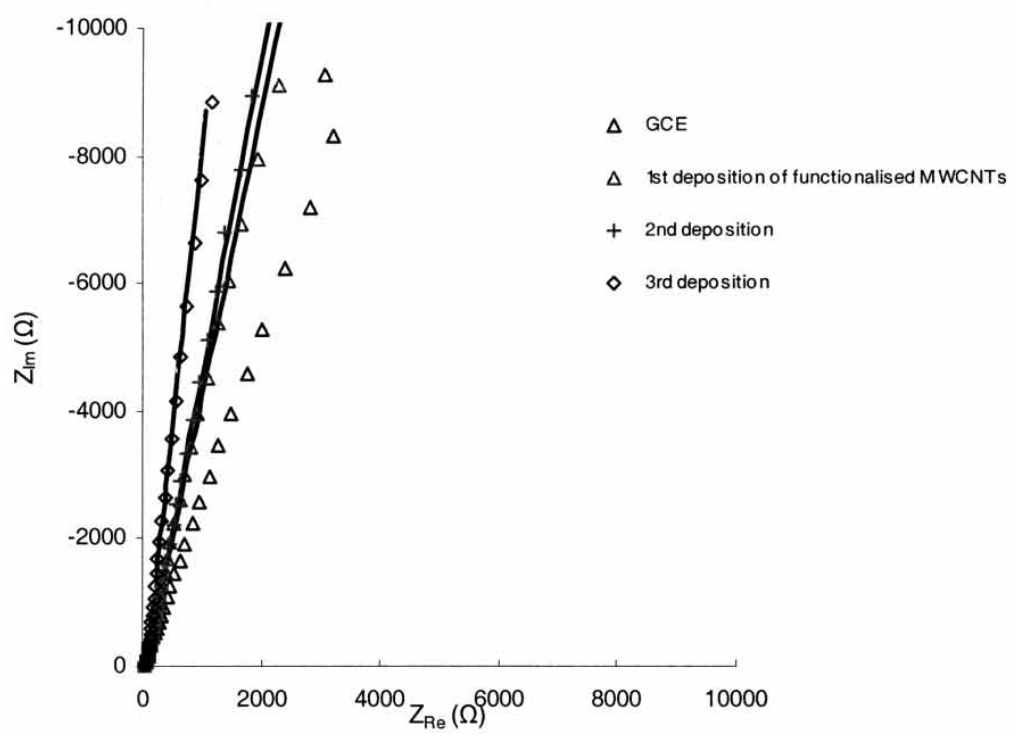

Figure 8. (a) Impedance spectra in the form of Nyquist plot for a glassy carbon electrode before and after modification with successive depositions of functionalised MWCNTs measured in the full frequency range of $0.1 \mathrm{~Hz}$ to $90 \mathrm{kHz}$. (b) is a magnified version of the low frequency range. The simulated curves, full lines, are calculated on the basis of an equivalent circuit (see text). 

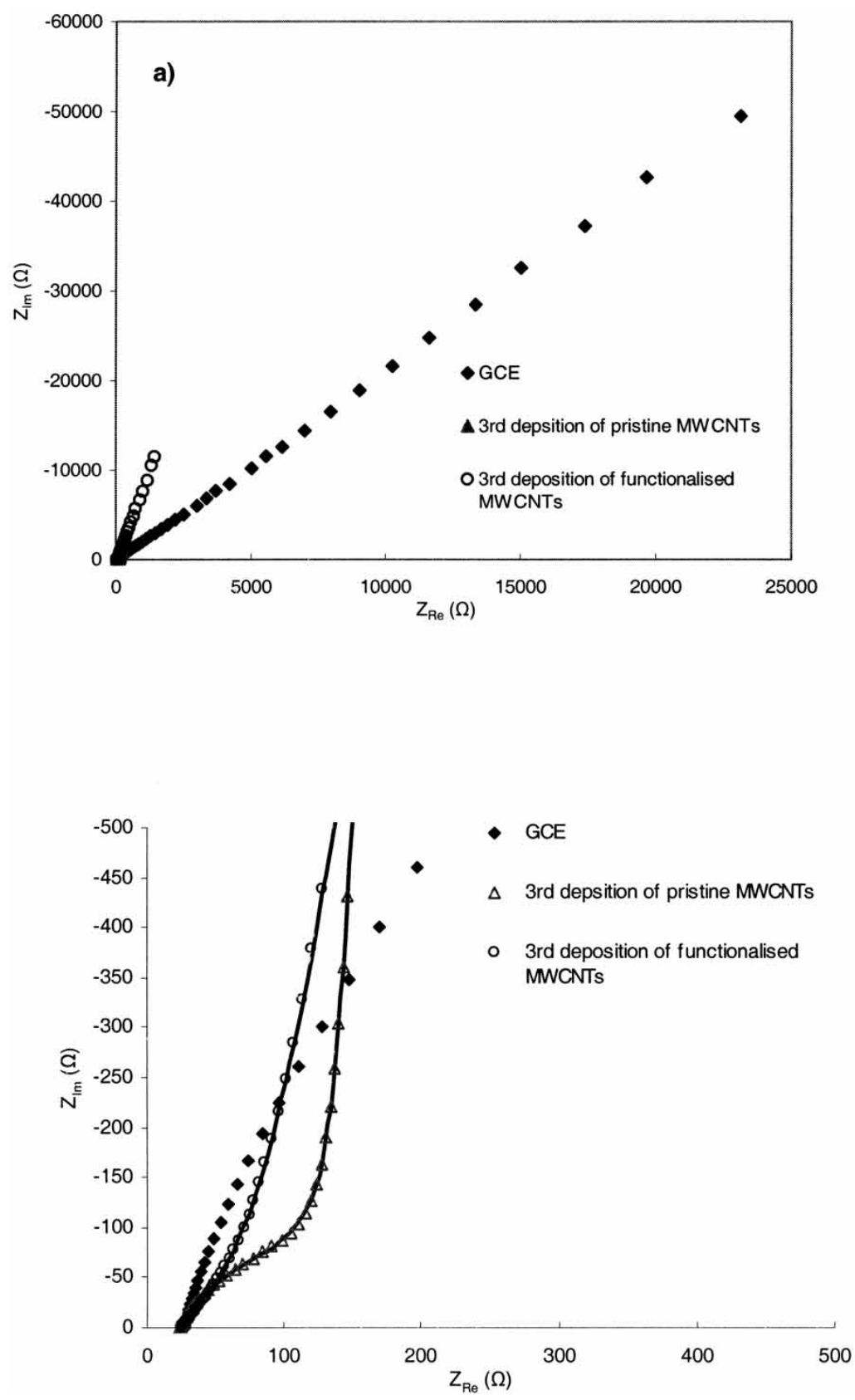

Figure 9. Comparison of Impedance spectra in the form of Nyquist and bode plots for a glassy carbon electrode before and after modification with 3 successive depositions of functionalised and pristine MWCNTs. 

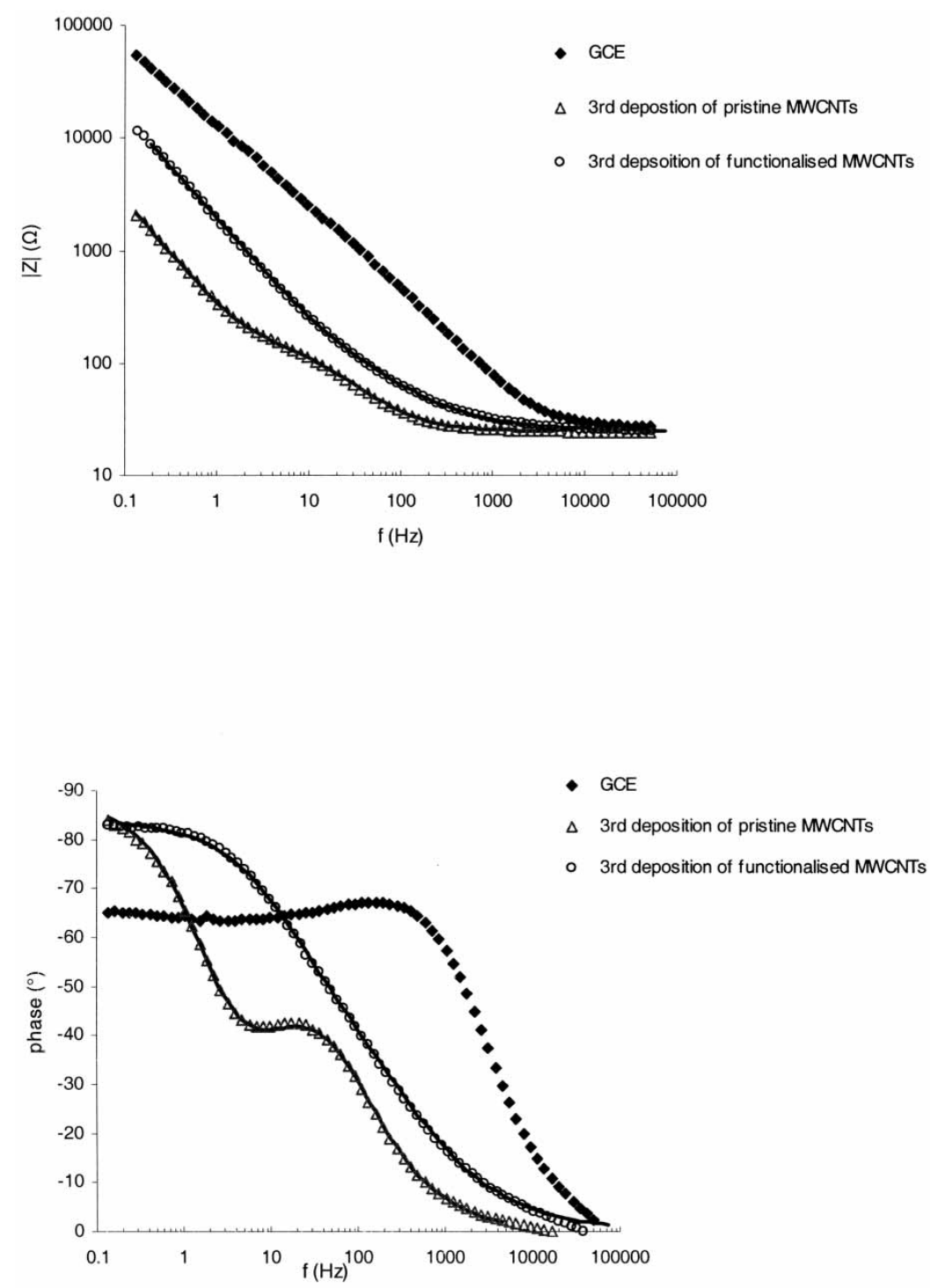

Figure 10.

functionalized MWNTs. $n$ this case EIS spectra include only a linear part. The semicircle is not present, after successive depositions.

Figure 9 compares Nyquist and Bode plots of the GCE and GCE modified with 3 successive depositions of pristine and functionalised nanotubes. At low frequencies the impedance of pristine nanotubes is almost vertical, its 
Table 2. Comparison of $\mathrm{C}_{\mathrm{dl}+\mathrm{p}}$ for pristine and functionalized nanotubes

\begin{tabular}{lll}
\hline & $\mathrm{C}_{\mathrm{dl}+\mathrm{p}}(\mathrm{F})$ & $\mathrm{a}_{\mathrm{dl}+\mathrm{p}}$ \\
\hline Functionalized MWCNTs & $9.4 \times 10^{-5}$ & 0.93 \\
Pristine MWCNTs & $5.47 \times 10^{-4}$ & 0.98 \\
\hline
\end{tabular}

magnitude has the lowest value and phase angle is close to that of an ideal capacitor $-90^{\circ}$. Table 2 summarizes the capacitance $\left(\mathrm{C}_{d l}+\mathrm{C}_{p}\right)$ values obtained from the fitting process in the low frequency range. The higher capacitance of pristine nanotubes correlates well with the large background current observed in the cyclic voltammetric results.

\section{CONCLUSIONS}

This work has provided an understanding of the role of oxygen functional groups on the electron transfer kinetics of MWNTs surfaces. The electrochemistry of $\mathrm{Fe}(\mathrm{CN})_{6}^{-3 /-4}$, redox analyte was investigated at glassy carbon electrodes modified with MWNTs before and after treatment in nitric acid by cyclic voltammetry and ac impedance spectroscopy, EIS. Apparently, voltammetric and EIS response indicated that acid treatment in $\mathrm{HNO}_{3}$ accelerates electron transfer. Acid treatment modifies the charge carrier density at the surface by introducing surface states and serves to facilitate electron transfer. The higher local density of states as compared to pristine MWNT could be responsible for favoring faster ET kinetics.

\section{REFERENCES}

1. Chen, P., Fryling, M.A., and McGreery, R.L. (1995) Electron transfer kinetics at modified carbon electrode surfaces: the role of specific surface sites. Anal. Chem., 67: 3115 .

2. Ranganathan, S., Kuo, T., and McCreery, R.L. (1999) Facile preparation of active glassy carbon electrodes with activated carbon and organic solvents. Anal. Chem., 71: 3574 .

3. Ranganathan, S. and McCreery, R.L. (2001) Electroanalytical performance of carbon films with near-atomic flatness. Anal. Chem., 73: 893.

4. Kiema, G.K. and Brett, M.J. (2003) Electrochemical characterisation of carbon films with porous microstructures. J. Electrochem. Soc., 150 (7): E342.

5. Banerjee, S., Kahn, M.G., and Wong, S.S. (2003) Rational chemical strategies for carbon nanotube functionalization. Che. Eur. J., 9: 1898.

6. Sinnott, S.B. (2003) Chemical functionalization of carbon nanotubes. J. Nanosci. Nanotech., 2: 113. 
7. Tasis, D., Tagmatarchis, N., Georgakilas, V., and Prato, M. (2003) Soluble carbon nanotubes. Chem. Eur. J., 9: 4001.

8. Ng, H.T., Fang, A.P., Li, J., and Li, S.F.Y. (2001) Flexible carbon nanotube membrane sensory system: a generic platform. J. Nanosci. Nanotech., 1 (4): 375.

9. Collins, P.G., Bradley, K., Ishigami, M., and Zettl, A. (2000) Extreme oxygen sensitivity of electronic properties of carbon nanotubes. Science, 287 (5459): 1801.

10. Valentini L., Lozzi, L., Cantalini, C., Armentaro, I., Kenny, J.M., Ottavio, L., and Santucci, S. (2003) Effects of oxygen annealing on gas sensing properties of carbon nanotube thin films. Thin Solid Films, 436: 95-100.

11. Nugent, J.M., Santhanam, K.S.V., Rubio, A., and Ajayan, P.M. (2001) Fast electron transfer kinetics on multiwalled carbon nanotube microbundle electrodes. Nanoletters, 1: 87.

12. Li, J., Cassell, A., Delzeit, L., Han, J., and Meayyappan, M. (2002) Novel threedimensional electrodes: electrochemical properties of carbon nanotube ensembles. J. Phys. Chem. B., 106: 9299.

13. Deakin, M.R., Stutts, K.J., and Wightman, R.M. (1985) The effect of pH on some outer sphere electrode-reactions at carbon electrodes. J. Electroanal. Chem., 182: 113 . 